\title{
Anomalous geoelectrical and geomagnetic signals observed at Southern Boso Peninsula, Japan
}

\author{
Ichiro Takahashi $\left({ }^{1}\right)\left({ }^{*}\right)$, Katsumi Hattori $\left({ }^{2}\right)$, Makoto Harada $\left({ }^{3}\right)$, Chie Yoshino $\left({ }^{2}\right)$ and Nobuhiro Isezaki $\left({ }^{2}\right)$ \\ (1) Graduate School of Science and Technology, Chiba University, Yayoicho, Chiba, Japan \\ ${ }^{(2)}$ Graduate School of Science, Chiba University, Yayoicho, Chiba, Japan \\ $\left(^{3}\right)$ Earthquake Prediction Center, Tokai University, Shinizu-Orido, Shizuoka, Japan
}

\begin{abstract}
Geoelectrical and geomagnetic fluctuations are considered the end product of several geophysical phenomena. In particular these signals measured in seismically active areas can be attributed to stress and strain changes associated with earthquakes. The complexity of this problem has suggested the development of advanced sophysticated methods to investigate the heterogeneous nature of these fluctuations. In this paper, we analyzed the time dynamics of short-term variability of geoelectrical potential differences and geomagnetic fields obsereved at Kiyosumi (KYS), Uchiura (UCU), and Fudago (FDG) stations, located in the southern part of Boso Peninsula, one of the most seismically active areas in Japan. Anomalous changes in electric and magnetic fields are obeserved in mid-night on October 6, 2002. the anomalous signals observed on October 6, 2002 are different from those originated from the train and other cultural noises according to the investigation on preferred directions of geoelectric field. The investigation of simaltaneous geomagnetic field changes suggest that the source of the electromagnetic change might be generated by underground current because of the polarity pattern oberved at KYS, UCU and FDG. Therefore, electrokinetic assumption under the ground seems one of the possible solutions for the generation of anomalous signals. It is important to understand the ULF electromagnetic environment for the study on the preparation process of crustal activity and systematic understanding both electromagnetic and seismic phenomena.
\end{abstract}

Key words ULF electromagnetic environment geoelectrical potential differences - direction of signal arrival - understanding the preparation process of crustal activity

\section{Introduction}

Electromagnetic phenomena are considered promising for the short-term prediction of large earthquakes (Hayakawa and Fujinawa, 1994; Hayakawa, 1999; Hayakawa and Molchanov, 2002)

Mailing address: Dr. Katsumi Hattori, Graduate School of Science, Chiba University, 1-33, Yayoicho, Inage-ku, Chiba 263-8522, Japan; e-mail: hattori@earth.s.chiba-u.ac.jp

(*) Now at: Marine Works Japan Ltd., Japan. and there have been convincing reports in a wide frequency range from DC to VHF. Measurements of electromagnetic phenomena can be classified into three types which are the passive groundbased observation (Fraser-Smith et al., 1990; Molchanov et al., 1992; Kopytenko et al., 1993; Lighthill, 1996; Hayakawa et al., 1996a, 2000; Hattori et al., 2002, 2004a; Uyeda et al., 2002; Hattori, 2004), the ground-based observation with the use of transmitter signals (Gokhberg et al., 1982; Gufeld et al., 1994; Hayakawa et al., 1996b; Molchanov and Hayakawa, 1998), and the satellite observation (Galperin and Hayakawa, 1996; Parrot, 1999). Among these observational methods, one of the most promising methods is a method of analyzing seismogenic ULF emissions because of deep skin depth observation (Fraser-Smith et al., 1990; Bernardi et al., 1991; 
Molcha-nov et al., 1992; Kopytenko et al., 1993; Lighthill, 1996; Hayakawa et al., 1996a, 2000; Hattori et al., 2002, 2004a; Uyeda et al., 2002; Hattori, 2004). In order to verify earthquake-related ULF electromagnetic phenomena and clarify the possible physical mechanisms, a network observation has been installed in Japan (Harada et al., 2004a,b).

Figure 1 shows a map of our ULF geoelectromagnetic stations at Boso Peninsula. This region is located in one of the most active seismic zones in Japan. There is a geoelectromagnetic sensor array with intersensor distance of about $5 \mathrm{~km}$. Torsion-type magnetometers with three components and two horizontal geoelectric fields are measured by pairs of electrodes, whose distance is about 30-50 m (Hattori et al., 2004b) are in operation.

The observed ULF geomagnetic and geoelectric potential data are consist of 1) signals originated from the external source field associated with the solar-terrestrial interactions such as geomagnetic pulsations and geomagnetic storms, and their inductive field, which appears simultaneously in the global (hundreds of $\mathrm{km}$ ) scale; 2) the regional (a few tens of $\mathrm{km}$ ) signals such as artificial noises associated with the leakage current from DC-driven trains, and earthquake-related signals; and 3) local (less than a few kms) signals around the sensors. The signals associated with the crustal activity are very weak in general, and therefore the signal separation is of critical importance.

In this paper, we apply Interstation Transfer Function (ISTF) (Harada et al., 2004a,b) method to the observed ULF geomagnetic and geoelectrical potential data to remove global variation mentioned above. We use geomagnetic data observed at Kakioka Magnetic Observatory, hereafter $\mathrm{KAK},\left(26.23^{\circ} \mathrm{N}, 140.19^{\circ} \mathrm{E}\right)$, Japan Meteorological Agency, as the remote reference data. We found anomalous variations in ULF geomagnetic and geoelectrical potential data in midnight on October 6, 2002 (JST). We also investigated the direction of signal arrival with the use of geoelectrical potential data observed at local midnight in order to identify the chracteristics of signals among background noises, intense transient artificial noises such as the leak currunt of DC driven trains, and the other signals using the potential gradient and we have analyzed signal characteristics at stations.

\section{ULF electromagnetic observation}

Figure 1 shows the map of stations at Southern Boso Peninsula. There is an array network with intersensor distance of about $5 \mathrm{~km}$. These stations are Uchiura (UCU), Kiyosumi (KYS), and Fudago (FDG). At each site, three components of geomagnetic field and two horizontal geoelectrical potential difference components are recorded with $50 \mathrm{~Hz}$ sampling (Hattori et al., 2004b). The clock is synchronized by GPS. At the reference site KAK, three geomagnetic fields are measured with $1 \mathrm{~Hz}$ sampling rate. Therefore, the data down sampled to $1 \mathrm{~Hz}$ have been used in this paper. Figure 2a-c indicates the configuration map of three stations.

The anomalous variations in geomagnetic and geoelectrical potential difference data are found at midnight. Figure 3a-f shows geomagnetic and geoelectric variations in the midnight during 00 h-04 h LT. For geomagnetic data (fig. 3a-c), the reference data are also plotted and it is smooth, on the other hand lower three curves simultaneously have transient variations in each component. Figure 3d-f shows geoelectrical potential differences at FDG, UCU, and KYS station, respectively. The strange transient changes in geomagnetic and geoelectrical potential difference data detected simultaneously. Around the station, intense artificial noises are originated from DCdriven train as shown in fig. 1, no DC-driven trains were passing through around the stations at this moment. These strange signals seldom observed at three stations simultaneously in midnight (after 01:00-03:00 JST). There are only seven times by eyes for analyzed four years data from 2000 to 2003.

\section{Removing global external variations with InterStation Transfer Function (ISTF)}

In order to enhance the strange variation clearly, the InterStation Transfer Function (ISTF) method with wavelet transform has been performed (Harada et al., 2004a,b). The ISTF meth- 


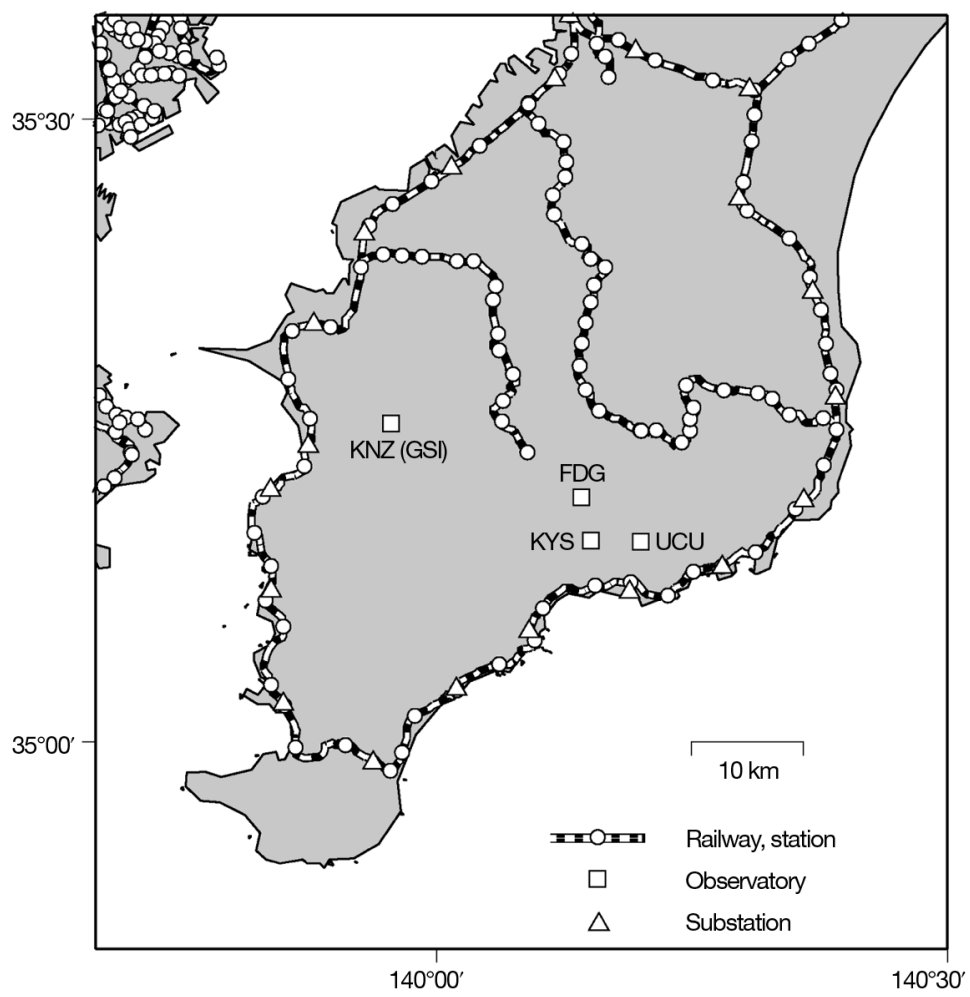

Fig. 1. The map of geoelectric and geomagnetic stations in Southern Boso Peninsula, Japan. KYS, UCU, and FDG indicate the stations. The railway lines are also shown.
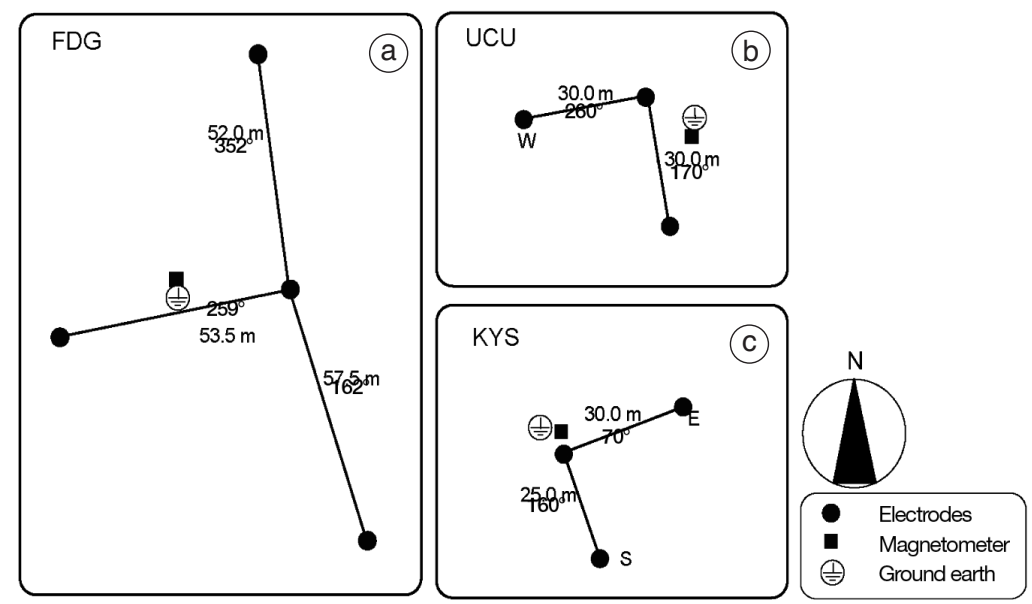

Fig. 2a-c. The configuration of ULF electromagnetic station. A 3 component magnetic sensor and electrodes for two horizontal geoelectrical potential measurements have been installed. a) FDG; b) UCU; and c) KYS station. 

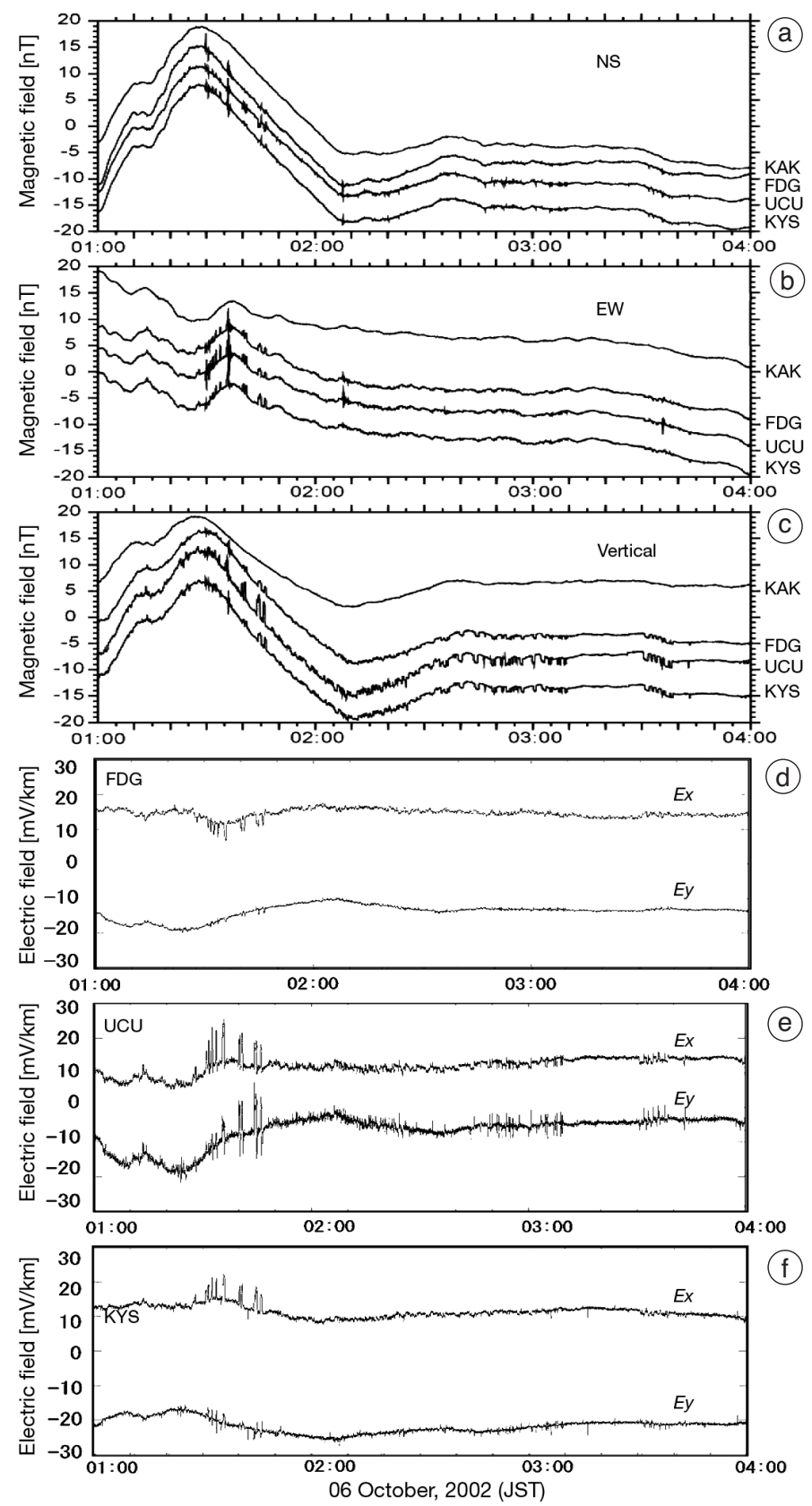

Fig. 3a-f. The observed data at interval of 01:00-04:00 on October 6, 2002 (JST). For magnetic field, remote reference data at KAK are also displayed for comparison and for the geoelectrical data, the data are normalized by baseline length. a) NS component of geomagnetic field; b) EW component of geomagnetic field; c) vertical component of geomagnetic field; d) geoelectrical potential data at FDG; e) geoelectrical potential data at UCU; and f) geoelectrical potential data at KYS. 


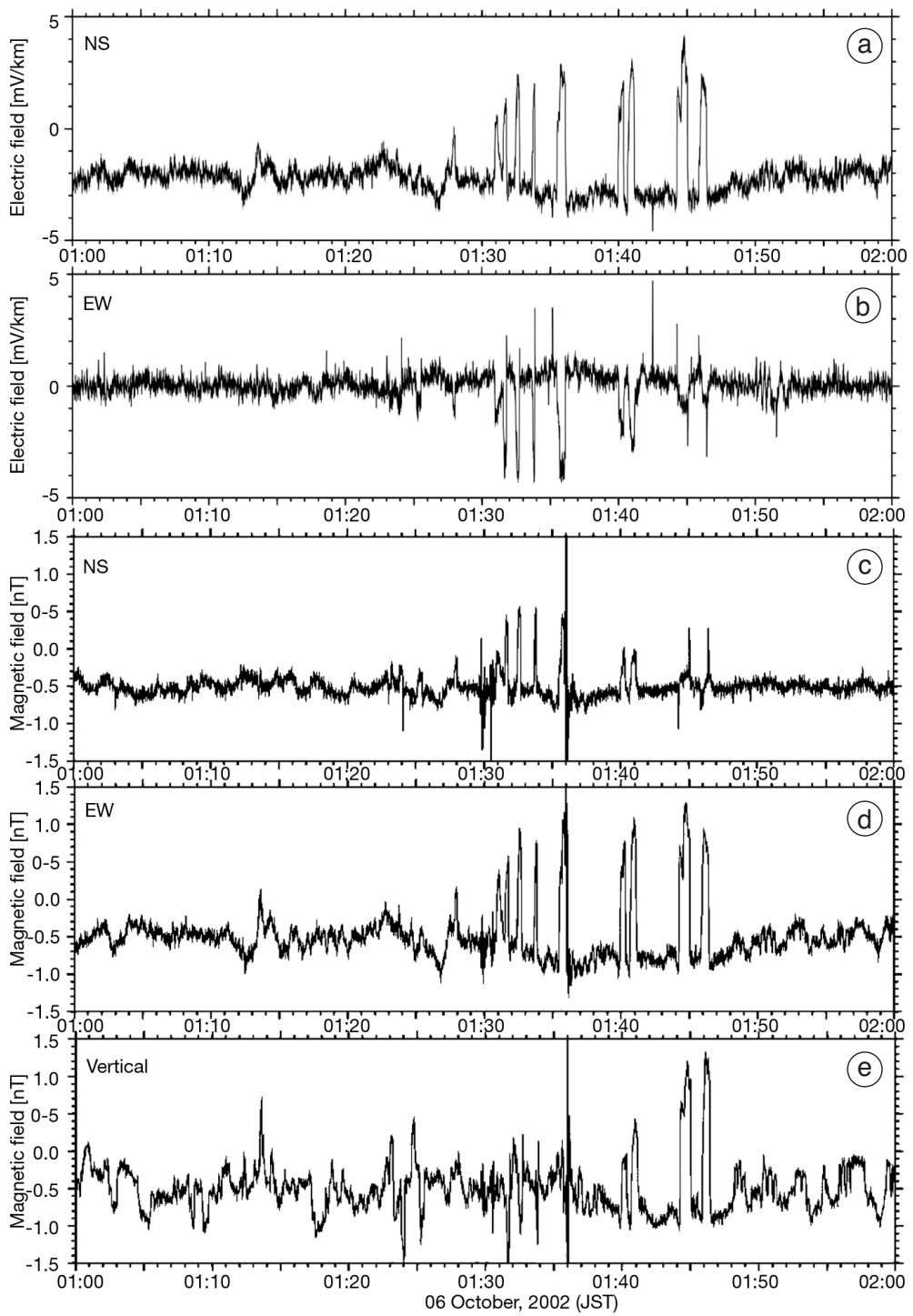

Fig. 4a-e. The results of global signal reduction with the use of ISTF and wavelet transform at KYS station. The displayed interval is from 01:00-02:00 on October 6, 2002 ( $T<940 \mathrm{~s}$ ). a) Geoelectrical variations (NS component); b) geoelectrical variations (EW component); c) geomagnetic variations (NS component); d) geomagnetic variations (EW component); and e) geomagnetic variations (vertical component).

od is based on the correlation between a site and a quiet remote reference station. ISTFs correspond to the correlation coefficients and have information on underground conductivity. We developed ISTF method to reduce variations due to global natural source in ULF geomagnetic data. That is, once ISTFs are estimated with high accuracy, which is considered to be invariant in time, it is possible to estimate the ideal geomagnetic variations originated from external solar- 
terrestrial interaction and their ideal inductive variations of the geoelectrical potential differences at the site using the reference data. Therefore, the residuals between the observed and estimated variations at the site provide only regional and local variations and earthquake-related phenomena are included. We use geomagnetic data observed at Kakioka Magnetic Observatory, Japan Meteorological Agency, as the remote reference data.

We applied the ISTF method to the data shown in fig. 3a-f. In computation, we use the ISTFs estimated in Harada et al. (2004a) for geomagnetic components and those for electromagnetic component for Harada et al. (2004b). The results at KYS station are shown in fig. 4a-e, where panel a, b and c-e are corresponding to the geoelectrical potential and geomagnetic variations, respectively. The strange change is well understood after reducing the global external variation. Especially, it is obvious in geomagnetic variation. Similar results have been obtained for UCU and FDG.

\section{Direction finding of geoelectrical potential data and polarity of geomagnetic data}

Baselines for potential measurements are not oriented to the real north-south and east-west direction as shown in fig. 2a-c. Therefore using an adequate rotation, observed values are projected to the actual NS and EW directions and this computation gives the gradient of potential or preferred orientation of the geoelectric field. The procedure is formulated by following equations:

$$
\begin{gathered}
V_{x}=\left(E_{y} \cos \omega-E_{x} \cos \theta\right) / \sin (\theta-\omega) \\
V_{y}=\left(-E_{y} \sin \omega+E_{x} \sin \theta\right) / \sin (\theta-\omega) .
\end{gathered}
$$

$V_{x}$ and $V_{y}$ correspond to the geoelectric fields of EW and NS component, resepectively. $E_{x}$ and $E_{y}$ mean the observed electric fields (potential/ baseline length) at a site. $\theta$ and $\omega$ are angles between the baselines and north direction. After plotting a $V_{x}-V_{y}$ map, the distribution of observed $V_{x}-V_{y}$ shows a not random but an elliptical pattern, in general. The direction of the line of apsides indicates the apparent direction of signal arrival around the site at the time. A geoelectric field projected to an arbitary direction $\phi$ from the north direction is given by

$$
V_{\phi}=\left(V_{x} \sin \phi+V_{y} \cos \phi\right)
$$

$\phi$ is corresponding to the most sensitive direction. This approach can be used for a noise reduction method. After the prefered direction of known signals such as a leak current of DC driven trains is determined, the observed data are projected to the orthogonal to the preferred direction and less fluctuation data set is reproduced, that is SNR is improved (Nagao et al., 2000; Uyeda et al., 2000).

The direction $\phi$ also shows the steepest gradient of additive potential difference in a short period. That is, if we assume the additive potential is generated by a point charge, the direction $\phi$ indicates the lication of the point charge.

In this paper, directions of geoelectrical signal arrival is investigated based on the latter concept at first. Figure 5a,b represents the strange signals observed at 01:30-02:00 on October 6, 2002 (JST) in geoelectric fields and geomagnetic fields, respectively. The strange transient signals are picked up and the moment of transient change are noted by sequential number. The waveform of strange signals are looks like rather rectangular one. Figure 6a,b shows signals associated with the DC-driven train at 05:0-05:30 on October 6, 2002 (JST) in geoelectric fields and geomagnetic fields, respectively. In a similar manner as indicated in fig. 5a,b, the times of the signal change are recorded. The waveform of the transient signals in figs. 5a,b and 6a,b looks like very similar. Therefore, a signal discrimination method is required to identify signal sources. The direction finding is one of the powerful tools for this aim.

Figures 7 and 8 show direction finding results of geoelectrical data for the anomalous signals and noises associated with the train, respectively. The number corresponds to that in figs. 5a,b and $6 a, b$. The arrows in the figure show the higher potential of the additive one. From fig. 7, it is found that the directions of geoelectrical field are faced to the southward of stations and they are stable. On the other hand, the signals associated with the train seem to move with following the train location as 

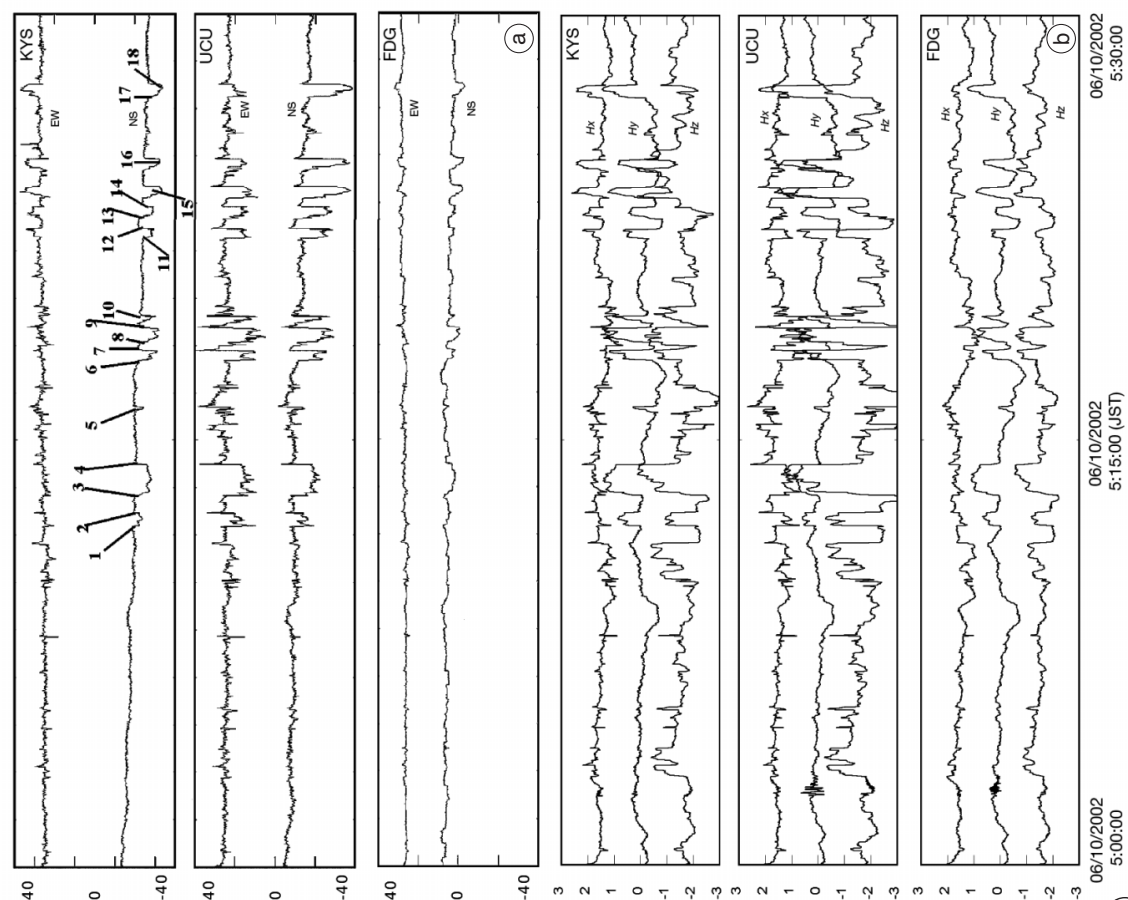

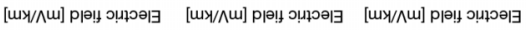

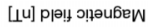

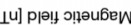

(6)
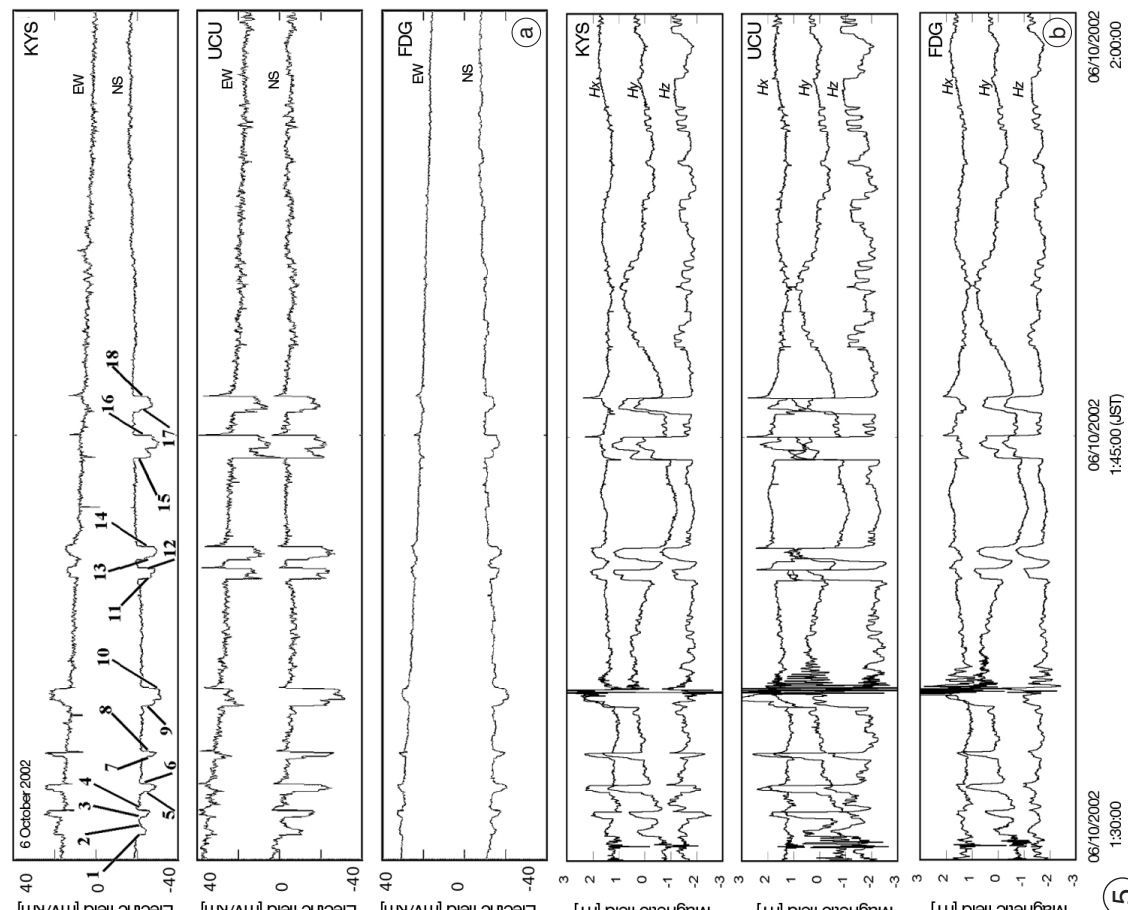

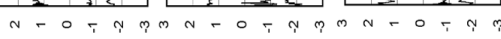

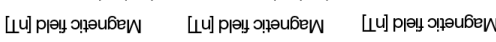

(6)

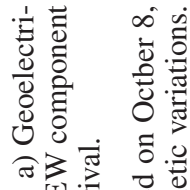

काष्य

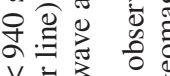

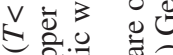

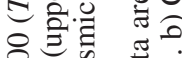

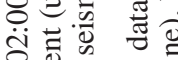

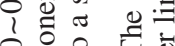

กํํㄹ

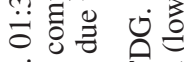

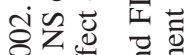

กัญ

๑๐。

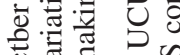

节至的艺

ن.

国

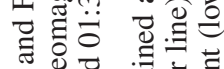

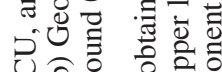

记。으을

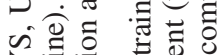

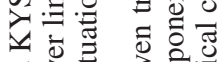



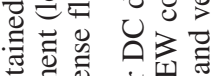

응.

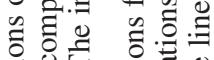

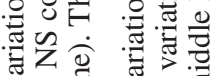

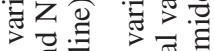

뭉 휴 뭉

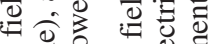

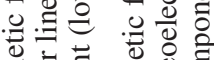

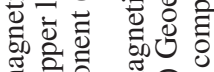

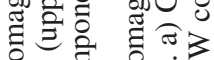

름

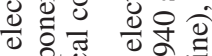

๑

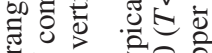

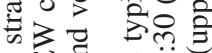

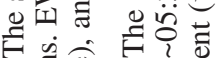

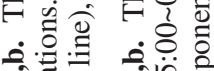

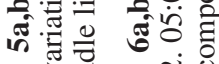

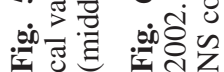



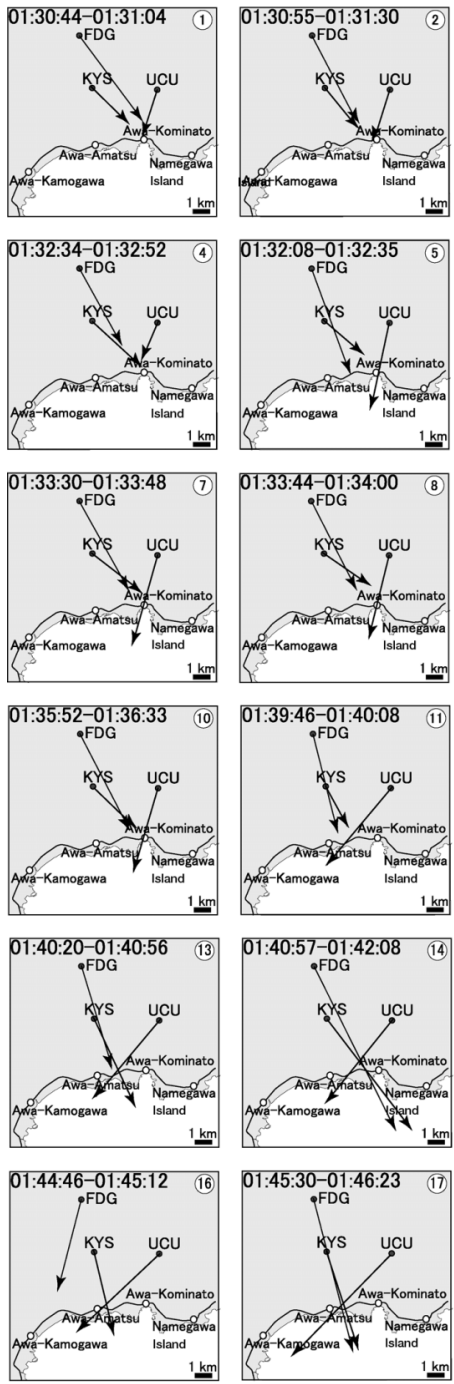

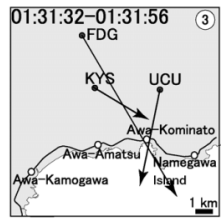

(7)
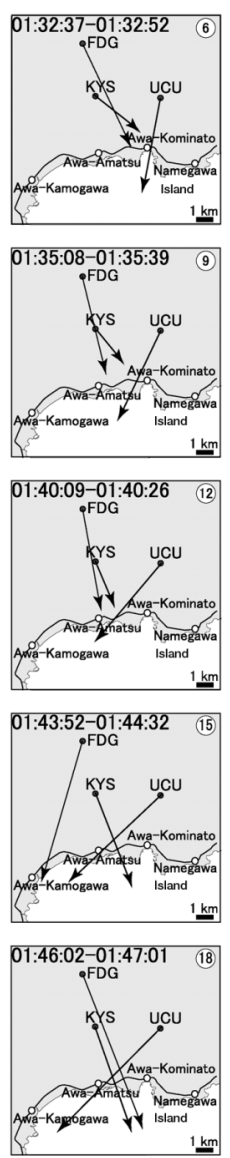
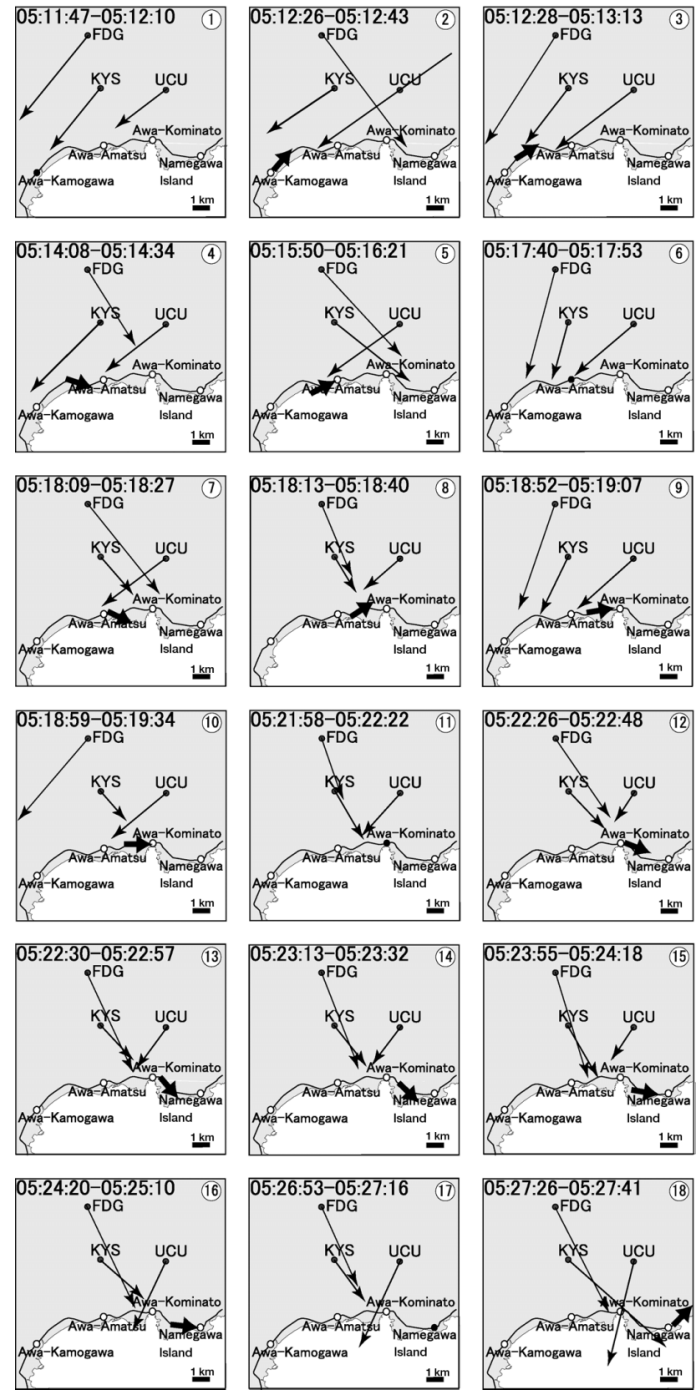

(8)

Fig. 7. Estimated directions of arrival for the strange signals on October 6, 2002 (described in fig. 6a,b), using preferred orientation investigation in geoelectrical data. The numbers correspond to those in fig. $6 \mathrm{a}, \mathrm{b}$.

Fig. 8. Estimated directions of arrival associated with DC driven train. The preferred orientation approach is adopted for geoelectrical data. The numbers correspond to those in fig. 7.

shown in fig. 8. These results suggest that the strange signals are not concerned with the train.

The characteristics of background noises at each station are also evaluated. Figure 9a-c shows the result and the direction seems to be oriented to the nearby village, radio wave equipment antenna and/or along the geographical condition such as a local valley, a stream or a river. 
Furthermore, we pay attention to polarities of geomagnetic changes at three stations. As shown in fig. 6a,b, the changes in geoelectrical potential differences and geomagnetic fields record exactly same time. The geomagnetic data at Kanozan station (KNZ), which is operated by Geological Survey Institute Japan and is located at $20 \mathrm{~km}$ northern part from our stations, (a)

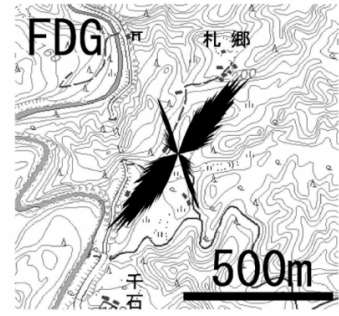

(b)

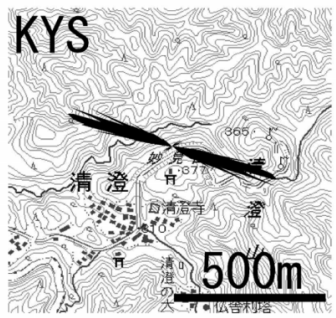

(C)

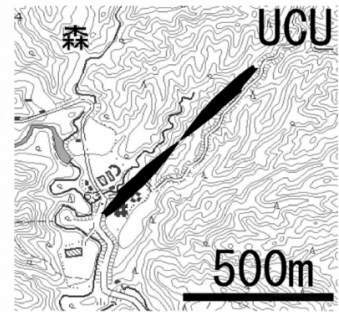

Fig. 9a-c. The estimated directions of arrival for the background noises. a) FDG; b) KYS; and c) UCU. The actual configuration of these stations is taken in account for this figure.
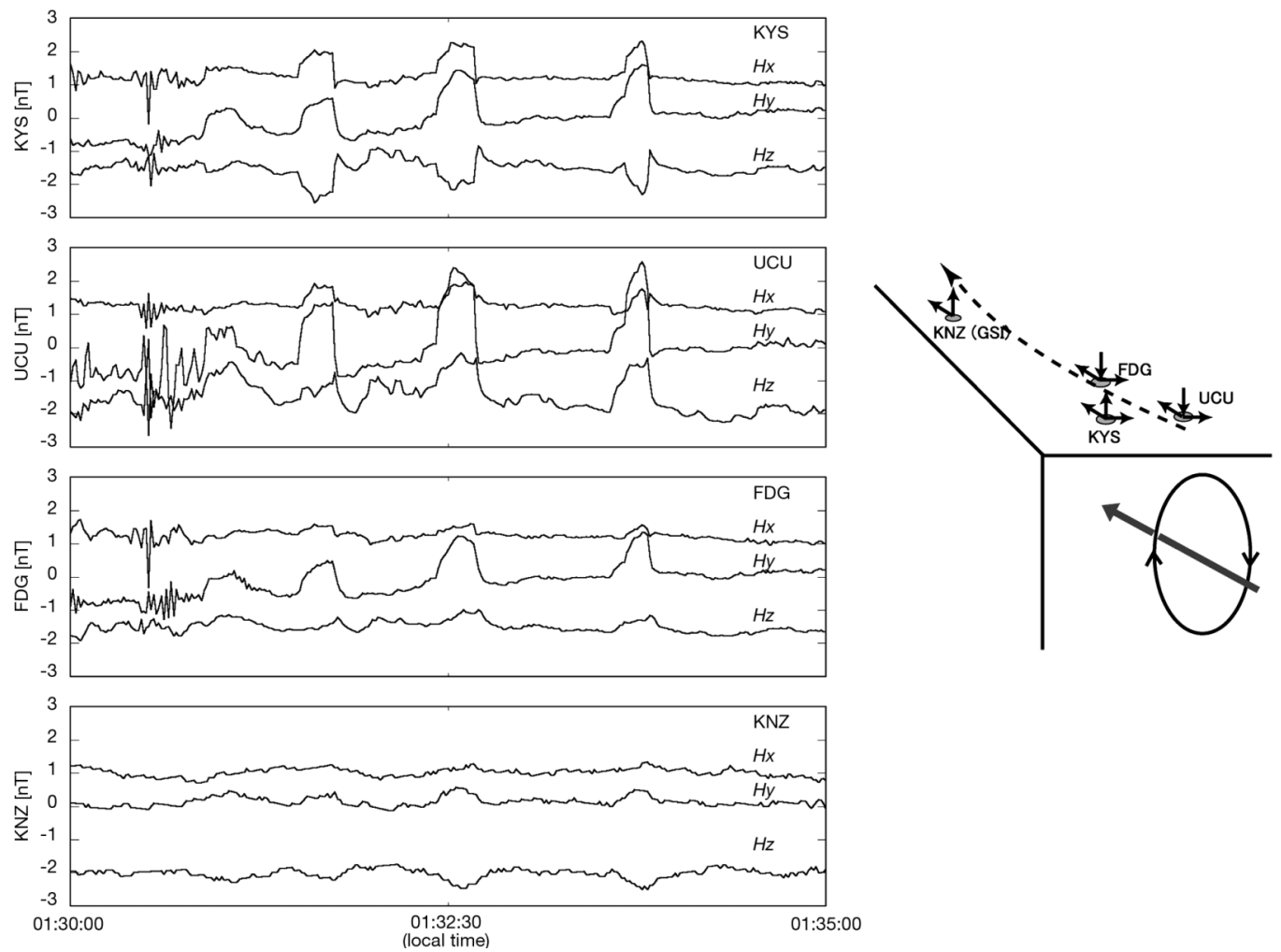

Fig. 10. The polarity pattern of geomagnetic fields at three stations from 01:30-01:35 on October 6, 2002 (JST) and estimated current source satisfied the observed polarity. 

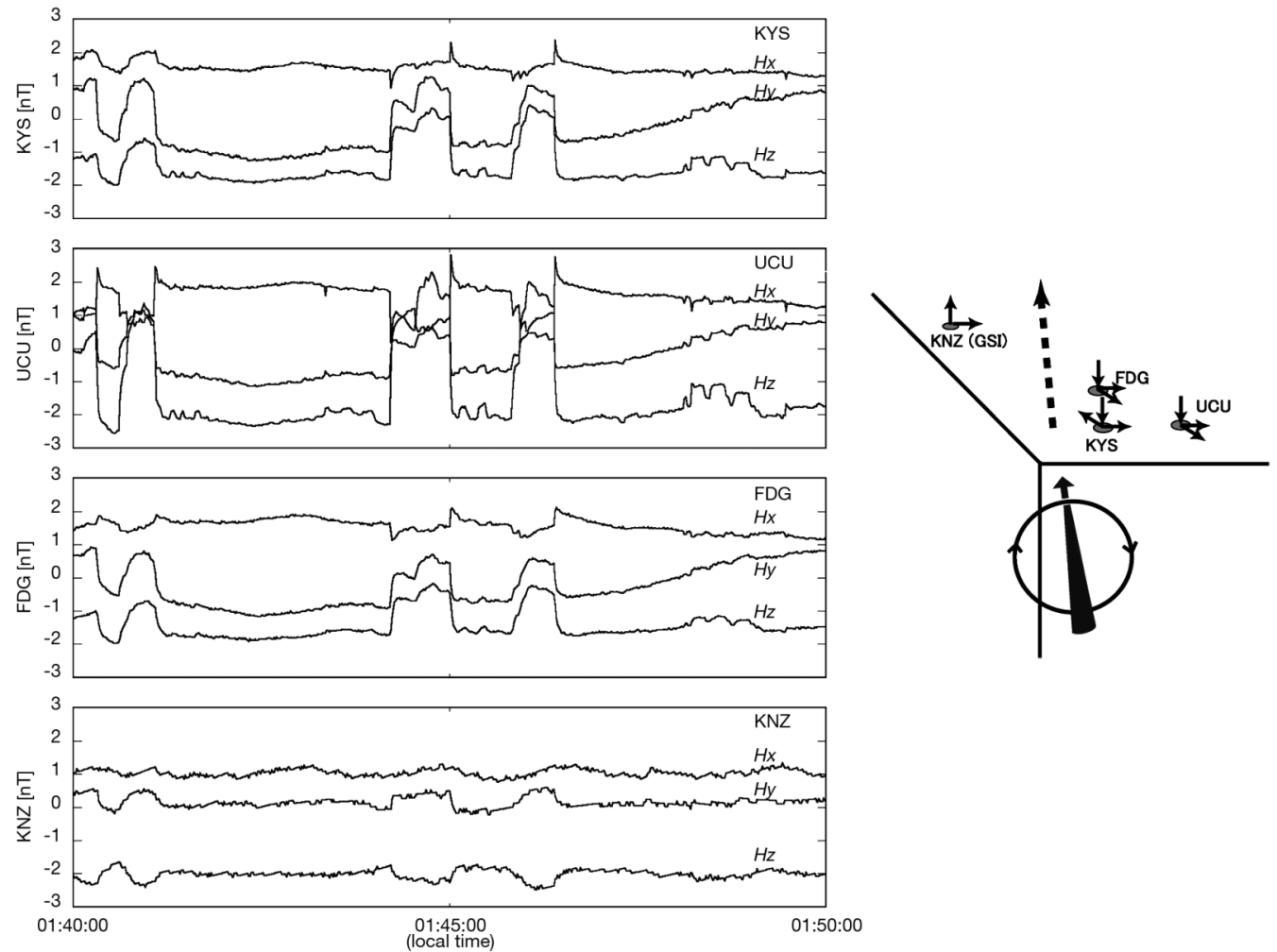

Fig. 11. The polarity pattern of geomagnetic fields at three stations from 01:40-01:50 on October 6, 2002 (JST) and estimated current source satisfied the observed polarity.

show the strange changes on October 6, 2002. On the other hand, there is no clear relation between train noises and data observed at Kanozan station. This result also suggest that the anomalous signals on October 6 are not train noises. The signals during the time interval 01:30-01:35 on October 6, 2006 (JST) are shown in fig. 10. The polarity of vertical component in KYS station is different from the other two stations (UCU and FDG). Taking account of polarity of horizontal component, it is reasonable to assume these signals are generated under the ground due to the current flow based on the electrokinetic process. That is, the source region under the ground could be estimated inside the triangle area and the direction of the fluid flow could be indicated by an arrow as shown in fig. 10. On the other hand, the polarity pattern a few hours later at three stations is presented in fig. 11 . The polarity is coherent among three station and the current flow under the ground may be changed as in fig. 11.

\section{Discussion and concluding remarks}

In this paper, the time series variation of geoelectrical potential and geomagnetic data was measured at KYS, UCU, and FDG, located at the southern part of Boso Peninsula, which is one of the most seismically active areas in Japan.

The directions of signal arrival were investigated to understand background and anomalous behaviors. External intense signal reduction with use of the interstation transfer function method 
have been also examined. These analyses have shown the capability to discriminate the signal sources. Especially, direction finding analysis of time series data has shown the effective source separation.

It is safe to say that the anomalous signals observed on October 6, 2002 are different from those originated from the train and other cultural noises according to the investigation on preferred directions of geoelectric field. Although the effective direction finding method does not exist for ULF geomagnetic field, the investigation on amplitude for quasi-static fields provides the consistent.

The investigation of simultaneous geomagnetic field changes suggest that the source of the electromagnetic change might be generated by underground current because of the polarity pattern oberved at KYS, UCU and FDG. Therefore, electrokinetic assumption under the ground seems one of the possible solutions for the generation of anomalous signals. In order to evaluate this hypothesis, the electrical underground structure around the stations should be determined. The observed signals at three stations should be explained clearly from the point of waveforms (amplitude and phase) by means of model computations based on the structure and assumed source region.

The anomalous variations in geoelectrical potential differences and geomagentic fields observed on October 6, 2002 during the active period of 2002 Boso slow slip event (Ozawa et al., 2003). Figure 12a,b shows the map of our sta-
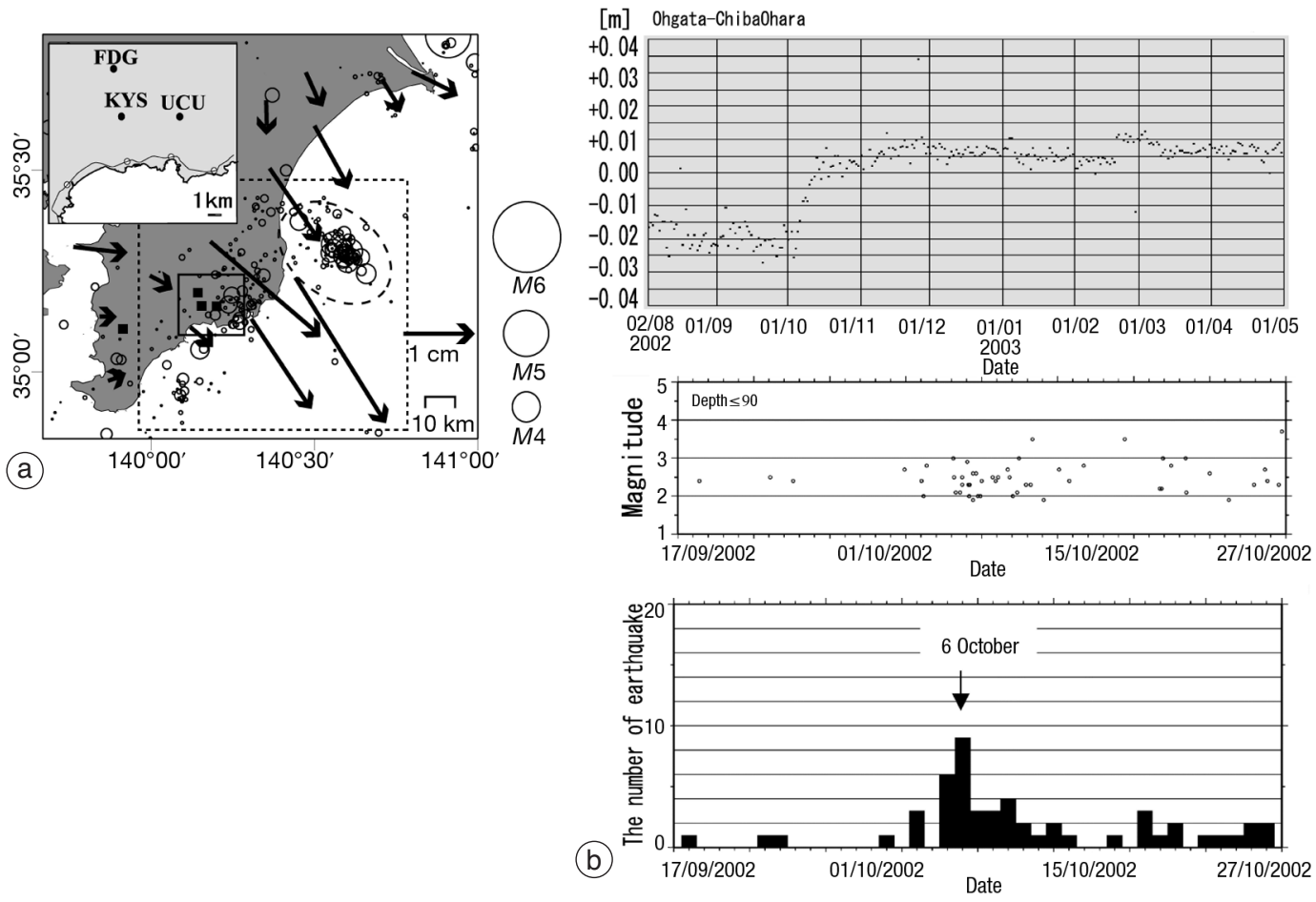

Fig. 12a,b. The 2002 Boso Slow Slip event and our stations. a) The rectangular region corresponds to the source region of the 2002 Boso Slip event. Vectors indicate the data of GPS deformation and small circles are epicenters. A broken circle indicate the small swarm activity on October 6, 2002. b) The variation of GPS deformation beween Ohgata and Ohara (after Ozawa et al., 2003). 
tion and the crustal activity. The rectangular area with broken lines in fig. 1 indicates a source region of the 2002 Boso Slow Slip Event. Slow slip event means a crustal activity without any mechanical vibrations like creep phenomena. This event was recorded by GPS deformation network. Figure 3a-f shows the results of GPS deformation measurement and there is a few $\mathrm{cm}$ displacement in early October. It is reported that the estimated displacement at the source region under the ground could be about $10 \mathrm{~cm}$ and the converted magnitude could be $M_{w} 6.6$ (Ozawa et al., 2003). This crustal activity is very unique because it is large and it occurred just below our small array network station.In addition, there starts a small swarm activity at the edge of the slow slip region on October 6, as shown fig. $12 \mathrm{a}, \mathrm{b}$.

It is not clear but there is a possibility that the anomalous signals might correlate with the slow slip event. Because the observation has been in operation since February 2000. Although daytime data are not used for the analysis because of contamination of train noises unfortunately, nighttime data are good in SN. We could not identify any similar change with large amplityde even at nighttime. The slow slip event is reported that the converted magnitude is greater than 6 and our station is just above the source region. During the active period of the slow slip event the stress might be complicated in the region and this may cause the unusual hydrological system. Then, the anomalous current is driven and anomalous signals due to electrokinetic scheme might be detected at the stations.

To identify waveform and/or to estimate direction of arrival are an important role in monitoring the ULF electromagnetic environment in seismic areas and for understanding the preparation process of crustal activity.

\section{Acknowledgements}

The authors wish to express their thanks to Kakioka Magnetic Observatory, Japan Meteorological Agency, for providing data. This work was partially supported by the JSPS Grants-inAid for Scientific Research \#16560360.

\section{REFERENCES}

Fraser-Smith, A.C., A. Bernardi, P.R. McGill, M.E. LADD, R.A. HeLliwell and O.G. JR. Villard (1990): Low-frequency magnetic field measurements near the epicenter of the $M_{s} 7.1$ Loma Prieta earthquakes, Geophys. Res. Lett., 17, 1465-1468.

GALPERIN, Y.I. and M. HAYAKAWA (1996): On the magnetospheric effects of experimental explosions observed from AUREOL-3, J. Geomagn. Geoelectr., 48, 1241-1263.

Gokhberg, M.B., V.A. Morgounov, T. Yoshino and I. Tomizawa (1982): Experimental measurement of electromagnetic emissions possibly related to earthquakes in Japan, J. Geophys. Res., 87, 7824-7828.

Gufeld, I.L., G. GuSEV and O. PoKhHOTELOV (1994): Is the prediction of earthquake date possibe by VLF radio wave monitoring method?, in Electromagnetic Phenomena Related to Earthquake Prediction, edited by M. Hayakawa and Y. Fujinawa (Terra Scientific Pub. Co., Tokyo), 381-390.

Harada, M., K. HatTori and N. IsEZAKI (2004a): Transfer function approach to signal discrimination of ULF geomagnetic data, Phys. Chem. Earth, 129, 409-417.

Harada, M., K. HATTORI and N. IseZAKI (2004b): Reduction of geomagnetic effects (periods $T<940 \mathrm{~s}$ ) from geoelectric potential difference data, Inst. Electr. Eng. Jpn., 124, 1245-1250.

HATTORI, K. (2004): ULF geomagnetic changes associated with large earthquakes, Terr. Atmos. Ocean. Sci, 15, 329-360.

Hattori, K., Y. Akinaga, M. Hayakawa, K. Yumoto, T. NaGAO and S. UYEDA (2002): ULF magnetic anomaly preceding the 1997 Kagoshima earthquakes, in SeismoElectroamgnetics: Lithosphere-Atmosphere-Ionosphere Coupling, edited by M. HAYAKAWA and O.A. MolCHANOV (Terra Scientific Pub. Co., Tokyo), 19-28.

Hattori, K., A. Serita, K. Gotoh, C. Yoshino, M. Harada, N. ISEZAKI and M. HAYAKAWA (2004a): ULF geomagnetic anomaly associated with 2000 Izu islands earthquake swarm, Japan, Phys. Chem. Earth, 29, 425-436.

Hattori, K., I. Takahashi, C. Yoshino, N. Isezaki, H. IWASAKI, M. Harada, K. KaWABATA, E. KopytenKo, Y. Kopytenko, P. Maltsev, V. Korepanov, O.A. MolchaNOV, M. HayakaWa, Y. Noda, T. Nagao and S. Uyeda (2004b): ULF geomagnetic field measurements in Japan and some recent results associated with Iwateken Nairiku Hokubu earthquake in 1998, Phys. Chem. Earth, 29, 481-494.

HAYAKAWA, M. (Editor) (1999): Atmospheric and Ionospheric Electromagnetic Phenomena Associated with Earthquakes (Terra Scientific Pub. Co., Tokyo), pp. 996.

HaYAKaWA, M. and Y. Fujinawa (Editors) (1994): Electromagnetic Phenomena Related to Earthquake Prediction (Terra Scientific Pub. Co., Tokyo), pp. 677.

HaYAKaWA, M. and O.A. Molchanov (Editors) (2002): Seismo-Electromagnetics: Lithosphere-AtmosphereIonosphere Coupling (Terra Scientific Pub. Co., Tokyo), pp. 477.

Hayakawa, M., R. Kawate, O.A. Molchanov and K. YUмото (1996a): Result of ultra-low-frequency magnetic field measurements during the Guam earthquake of 8 August 1993, Geophys. Res. Lett., 12, 241-244.

Hayakawa, M., O.A. Molchanov, T. ONDOH and E. KawaI 
(1996b): Anomalies in the subionospheric VLF signals for the 1995 Hyogo-ken Nanbu earthquake, J. Phys. Earth, 44, 413-418.

HAYAKAWA, M., T. Itoh, K. HatToRi and K. Yumoto (2000): ULF electromagnetic precursors for an earthquake at Biak, Indonesia on February 17, 1996, Geophys. Res. Lett., 27, 1531-1534.

Kopytenko, Y.A., T.G. Matishvili, P.M. Voronov, E.A. Kopytenko and O.A. Molchanov (1993): Detection of ultra-low-frequency emissions connected with the Spitak earthquake and its aftershock activity, based on geomagnetic pulsations data at Dusheti and Vardzia observatories, Phys. Earth Planet. Inter, 77, 85-95.

Lighthill, J. (1996): A Critical Review of VAN (World Scientific, Singapore), pp. 376.

Molchanov, O.A. and M. Hayakawa (1998): Subionospheric VLF signal perturbations possibly related to earthquakes, J. Geophys. Res., 103, 17489-17504.

Molchanov, O.A., Y.A. Kopytenko, P.M. Voronov, E.A. Kopytenko, T.G. Matiashvili, A.C. Fraser-Smith and A. Bernardi (1992): Results of ULF magnetic field measurements near the epicenters of the Spitak $\left(M_{s}=6.9\right)$ and Loma Prieta $\left(M_{s}=7.1\right)$ earthquakes: com- parative analysis, Geophys. Res. Lett., 19, 1495-1498.

NagaO, T., Y. ORIHARA, T. YAmaguchi, I. TAKahashi, K. Hattori, Y. Noda, K. SAYANAgI and S. Uyeda (2000): Co-seismic geoelectric potential changes observed in Japan, Geophys. Res. Lett., 27, 1535-1538.

Ozawa, S., S. Miyazaki, Y. Hatanaka, T. Imakime, M. KAIZU and M. MuraKAMI (2003): Characteristic silent earthquakes in the eastern part of the Boso Peninsula, Central Japan, Geophys. Res. Lett., 30, 1283.

PARrot, M. (1999): Statistical studies with satellite observation of seismogenic effects, in Atmospheric and Ionospheric Electromagnetic Phenomena Associated with Earthquakes, edited by M. HAYAKAWA (Terra Scientific Pub. Co., Tokyo), 685-695.

Uyeda, S., T. NAGAO, Y. ORIHARA, T. YAMAGUChI and I. TAKAHASHI (2000): Geoelectric potential changes: possible precursor to earthquakes in Japan, PNAS, 97, 4561-4566.

Uyeda, S., M. Hayakawa, T. Nagao, O.A. Molchanov, K. Hattori, Y. Orihara, K. Gotoh, Y. Akinaga and H. TANAKA (2002): Electric and magnetic phenomena observed before the volcano-seismic activity 2000 in the Izu islands region, Japan, Proc. US Nat. Acad. Sci., 99, 7352-7355. 